\title{
CONSTITUCIONALISMO DIALÓGICO: UMA FORMA DE PARTICIPAÇÃO POPULAR EFETIVA ${ }^{1}$
}

\author{
Marina Cristina Schmaltz Rocha ${ }^{2}$
}

RESUMO: O artigo discorre sobre o constitucionalismo latino-americano, suas fases e sua contemporaneidade. O objetivo desse trabalho é trazer o histórico do constitucionalismo latinoamericano, e ainda, analisar sua atual situação, com foco no novo constitucionalismo dialógico, proposto pelo professor Roberto Gargarella. Trata-se de pesquisa bibliográfica. Conclui-se que o atual constitucionalismo de alguns países latino-americanos precisa implementar uma política dialógica ou deliberativa, a qual a participação popular é fundamental na tomada de decisões públicas.

PALAVRAS-CHAVES: Constitucionalismo dialógico; Constituição; participação popular; pluralidade; democracia.

\section{DIALOGICAL CONSTITUTIONALISM: A FORM OF EFFECTIVE POPULAR PARTICIPATION}

\begin{abstract}
The article deals with Latin American constitutionalism, its phases and its contemporaneity. The objective of this work is to bring the history of Latin American constitutionalism and analyze its current situation, focusing on the new dialogical

\footnotetext{
${ }^{1}$ Artigo científico apresentado como requisito parcial de aprovação na disciplina "Jurisdição internacional", ministrada pelo Prof. Dr. Eduardo Val no programa de pós-graduação da Universidade Estácio de Sá/RJ, na modalidade de Doutorado Interinstitucional em parceria com a Unianhanguera/GO.

${ }^{2}$ Doutoranda em Direito Público no programa de pós-graduação da Universidade Estácio de Sá/RJ, na modalidade de Doutorado Interinstitucional em parceria com a Unianhanguera/GO; advogada e professora universitária.

E-mail: schmaltz.marina@gmail.com
} 
constitutionalism proposed by Professor Roberto Gargarella. This is a bibliographical research. It is concluded that the current constitutionalism of some Latin American countries needs to implement a dialogical or deliberative policy, which popular participation is fundamental in public decision-making.

KEY-WORDS: Dialogical constitutionalism; Constitution; popular participation; plurality; democracy.

\section{INTRODUÇÃO}

O trabalho aborda o novo constitucionalismo dialógico, erigido pelo professor Roberto Gargarella, que discorre que esse novo constitucionalismo preza pela autonomia individual como mecanismo de participação popular na tomada de decisão.

$\mathrm{O}$ atual constitucionalismo latino-americano conquistou um avançado rol de direitos, o que incluiu a todos os povos, dentre eles os indígenas, os trabalhadores, entre outros, porém o problema reside na parte organizacional do sistema, o qual concentra todo o poder nas mãos das autoridades públicas, dos Poderes da República, o que de fato, elimina a participação popular nas decisões.

A atual organização política da América Latina está pautada em estruturas velhas e elitistas, que concentram o poder nas autoridades públicas, abolindo as ferramentas de emancipação popular.

Esse é um tema de debate atualmente, pois muitos estudiosos se dedicam a aprofundar no constitucionalismo latino-americano, momento no qual esses autores tentam trabalhar nas soluções para o aprimoramento das democracias latino-americanas. Esse trabalho traz algumas dessas soluções para o melhor desenvolvimento dos sistemas políticos da América Latina. A metodologia utilizada será bibliográfica, que se baseará em pesquisas anteriores.

Nesse trabalho, desenvolver-se-á a parte histórica do constitucionalismo latinoamericano, logo, far-se-á uma explanação sobre o atual constitucionalismo latino-americano, e por último, apresenta-se quais são os impasses desse novo constitucionalismo e quais são as possíveis respostas para o seu aprimoramento. 


\section{DESENVOLVIMENTO}

\section{A HISTÓRIA DO CONSTITUCIONALISMO LATINO AMERICANO}

O professor Roberto Gargarella tece comentários sobre o histórico do Constitucionalismo latino-americano. O autor afirma que a maioria dos países Latinoamericanos entraram no século XX (1850-1910) com Constituições liberais-conservadoras, isto é, com Constituições que tinham ideais tanto liberais quanto conservadores, tais como, a característica do sistema de freios e contrapesos de cunho liberal, a qual consiste em um Poder controlar, fiscalizar o outro a fim de obter equilíbrio. Do outro lado, tem-se o ideal conservador que busca a centralização do Poder, ou seja, o Poder está concentrado nas mãos das autoridades, principalmente no Poder Executivo, o que por sua vez, dá margem a criação de um "superpoder", ou melhor, de um "hiperpresidencialismo", denominado assim pelo próprio professor Gargarella.

Já previamente, sustenta-se que esse "hiperpresidencialismo" gera uma certa desconfiança na cidadania, isto é, nas participações populares nas decisões políticas ou econômicas, pois essa farta atuação do Poder Executivo inibe a participação popular.

Após o período liberal-conservador, sobreveio o período do constitucionalismo social (1910-1950), impulsionado pela Constituição do México de 1917, como consequência da Revolução do México (1910). Essa nova Constituição mexicana era repleta de direitos sociais, uma completa novidade ao seu tempo, sendo a primeira Constituição no mundo a conter direitos sociais ampliados. Em meio ao surgimento da Constituição Mexicana de 1917, alguns outros países latino-americanos seguiram a mesma ideia: o Brasil modificou sua Constituição em 1937; a Bolívia em 1938; Cuba em 1940; Uruguai em 1942; Equador e Guatemala em 1945; e Argentina e Costa Rica em 1949. Assim, esse período do constitucionalismo social é marcado pela presença, mormente, da classe trabalhadora, como protagonista na cena política e econômica.

Com referência ainda ao período do constitucionalismo social, foi um período de avanço social, porém sem evolução quanto à participação popular nas decisões, o Poder continuava concentrado nas autoridades públicas. 
Em seguida desses dois períodos, surge o período do multiculturalismo e direitos humanos (1950-2010), o qual vários países modificaram suas Constituições: o Brasil mudou sua Constituição em 1988, a Colômbia em 1991, a Argentina em 1994, a Venezuela em 1999, o Equador em 2008, a Bolívia em 2009 e o México em 2011. Nesse tempo de 1950 a 2010, vários países sofreram com os regimes autoritários, que trouxeram tortura, repressão, privação de direitos civis, políticos e censura. Com efeito, ao final dessa era de regimes déspotas, os países latino-americanos cambiaram o curso da história, com as Constituições abundantes em direitos sociais.

Assim, esse último período do constitucionalismo latino-americano foi marcado pelas Constituições que defendem os direitos humanos (GARGARELLA, 2014, 2013). Contudo, atualmente, ainda é preciso muito para se efetivar a democracia deliberativa ou dialógica, aquela em que a participação popular é fundamental e básica na tomada de decisões do país.

\section{O ATUAL CONSTITUCIONALISMO LATINO-AMERICANO}

Hodiernamente, vive-se a ascensão do Constitucionalismo Latino-Americano, que prima pelo reconhecimento das pluralidades sociais, culturais, políticas e jurídicas, e que objetiva dar voz às diversas experiências emancipatórias que ocorrem no mundo, não privilegiando segmentos societários em detrimento de outros.

Esse Constitucionalismo Latino-Americano está adstrito ao novo constitucionalismo dialógico proposto por Roberto Gargarella, pois ambos buscam a inserção da participação popular nos processos de tomada de decisões.

Primeiramente, deve-se atentar para as várias visões de mundo, e notar que a diversidade cultural, política, social, jurídica é inesgotável. Assim, não é possível aceitar uma teoria geral advinda de outra realidade como máxima a ser perquirida pelo país local, pois, geralmente, essas teorias não são compatíveis com o ambiente social regional, que deve ver, respeitar e analisar as suas características locais.

Insta salientar que a luta pela igualdade somente pode ser verdadeira quando também se luta pelo reconhecimento da diferença.

Pode-se afirmar que existe uma crise de identidade entre indivíduo e nação, devido ao fato de que algumas vezes o cidadão não se sente representado pela sua nação, por ser diferente daquilo que a nação figura ser. Isso constitui uma contradição da sociedade contemporânea, e 
deve ser extirpada por meio do reconhecimento de todos os povos pertencentes a uma mesma nação.

O Constitucionalismo Latino-Americano propõe práticas alternativas, tais como, resolução de problemas através da implementação de diversas áreas do saber, por exemplo, resolver questões sobre a inflação, não apenas produzindo análises críticas econômicas, mas também, fazendo análises das abordagens do ponto de vista jurídico, sociológico, administrativo e etc.

Subjacente ao conhecimento, à educação, o autor Boaventura de Sousa Santos, (2007c, p.09), expõe uma de suas ecologias, como "a ecologia dos saberes, que postula um diálogo do saber científico com o saber popular e laico; esta ecologia considera outros saberes, e não um saber único, sem olvidar o seu próprio conhecimento". Desta feita, o autor aponta a importância da consideração dos diversos saberes, das variadas ciências, e não somente considerar uma única ciência como válida e plausível.

Outra prática alternativa é admitir e respeitar a intensificação do surgimento de movimentos como agentes transformadores. Acontece que os partidos políticos, juntamente com o Congresso Nacional, no caso da República Federativa do Brasil, não são mais os únicos detentores da vontade popular, há outras figuras que também defendem a diversidade social, como é o caso dos referidos movimentos e de algumas organizações civis. Por isto, é salutar que se perfaça uma cooperação entre partidos políticos e movimentos, para que se auxiliem e não criem conflitos entre si.

Ademais, esse Constitucionalismo Latino-americano ainda precisa ser aprimorado, pois ainda possui características conservadoras que trazem desigualdade. Ainda existem problemas estruturais nas democracias latino-americanas, por exemplo, os cidadãos ainda não conseguem promover uma "accountability", isto é, um controle, uma fiscalização, ou até mesmo, uma participação efetiva nas decisões políticas, econômicas do país (ROCHA, 2014).

O mais adequado seria abrir as decisões políticas e sociais para uma discussão na sociedade, assim como Peter Haberle afirma em sua obra "A sociedade aberta aos intérpretes da Constituição", todos devem interpretar a Constituição, sejam órgãos estatais, cidadãos, enfim, todos, sem exceções devem fazer a exegese da Constituição, sem que possa assim definir uma lista exaustiva de quem pode interpretar a Constituição. A hermenêutica constitucional tem sido até agora, pouco inclusiva, está ainda fechada. 
A interpretação da Constituição é um elemento da sociedade aberta, e essa interpretação será mais aberta se a sociedade for cada vez mais pluralista. Assim, um cidadão que vive sob uma norma regulamentada, faz parte diretamente do processo de interpretação, pois a norma, a lei é feita para ele. Disso, conclui-se que os intérpretes jurídicos fazem as interpretações conforme sua expertise, porém eles não possuem o monopólio da interpretação da Constituição, pois as normas não são elaboradas somente para eles.

A interpretação da norma não é algo acabado, simples, prévio, é algo pluralizado, com efeito, todos devem interpretar a Constituição, até mesmo aqueles que não são afetados diretamente pela norma. Limitar a interpretação constitucional aos intérpretes jurídicos ou ao Estado significa um empobrecimento.

Povo não significa apenas o "quantitativo" que vota no dia das eleições, e assim legitima o processo democrático, povo é antes de tudo a representação pluralista da sociedade. Democracia é formada por associação de cidadãos, democracia é o domínio de cidadãos, não se deve ter em mente apenas aquela concepção tradicional de democracia.

\title{
3. O PROBLEMA APONTADO POR ROBERTO GARGARELLA
}

O professor Gargarella aponta um imbróglio para o novo constitucionalismo latinoamericano, segundo ele, criou-se muitos direitos, porém olvidou-se da organização dos Poderes.

De acordo com o professor Gargarella $(2014,2013)$ :

\begin{abstract}
Reformistas legais mantém fechadas as portas da "sala de máquinas" da Constituição: o núcleo da maquinaria democrática não é modificado. A máquina da Constituição não se transforma no objeto de atenção principal dos reformadores. É como se a sua missão estivesse concluída com o trabalho nas seções dos direitos, como se os controles principais somente pudessem ser tocados pelos aliados mais próximos daqueles que estão no poder.
\end{abstract}

Em consonância com o citado acima, o professor Gargarella denuncia a falta de participação popular nas decisões políticas, econômicas, culturais, sociais de um país, a qual retira qualquer poder dos cidadãos, o que deixa nas mãos apenas das autoridades públicas todas as decisões de uma nação. Esse é o retrato do atual constitucionalismo latino-americano, enraizado com atributos do século XIX.

É como diz Roberto Gargarella (2014,2013): 


\begin{abstract}
Evidentemente que o problema com as novas Constituições não é simplesmente que elas não foram longe o bastante de modo a alcançar a "sala de máquinas" da constituição. Se esse fosse o problema, a solução poderia simplesmente ter sido esperar até a próxima reforma. O problema é que, preservando uma organização de poderes que permanece arranjada debaixo de um modelo do século XIX de concentração de autoridade, as novas Constituições colocam em risco as mesmas iniciativas que elas avançaram através das seções de direitos.
\end{abstract}

Destarte, afere-se a posição do autor no sentido de criticar a conservadora organização política vertical, a qual um indivíduo tem mais poder sobre o outro, sobretudo, os poderes públicos, que inviabilizam as iniciativas populares (GARGARELLA, 2014, 2013). Portanto, o autor afirma que essa organização política vertical é incompatível com a lista de direitos avançados.

O autor ainda prossegue e afirma que atualmente, de um lado a Constituição constitui direitos, garante o exercício dos direitos, no entanto, do outro lado, essa mesma Constituição está arraigada nas estruturas antigas, essas que não permitem participação efetiva da cidadania na política, na economia do país, isso significa que a população não tem acesso à "sala de máquinas" da Constituição, isto é, o povo não tem acesso onde são decididas as questões políticas, econômicas, sociais, culturais do país.

Assim, denota-se que as novas Constituições trouxeram novos direitos sociais, multiculturais. A dificuldade reside no fato de que esses novos direitos estão sufocados em estruturas institucionais e organizacionais antigas, que não viabilizam a real efetivação dos novos direitos. A atual organização dos Poderes, da maneira que está estruturada não permite participação popular, não concede o empoderamento da cidadania.

Outrossim, o grande emblema encontrar-se no fato de que não se pode requerer a desconcentração de poder àqueles que estão no Poder, isso seria ilógico. Além disso, o poder popular quase sempre foi visto com aclamação ou como um poder fiscalizador, e nunca como um poder autônomo, que seria o ideal, mas o poder popular visto como um poder autônomo seria uma ameaça ao "hiperpresidencialismo" que já está instaurado no sistema político.

Enfim, as Constituições latino-americanas permitiram o acesso da população, sobretudo das minorias, aos direitos, ainda que com atraso, não obstante o acesso à "sala de máquinas" da Constituição ainda permanece inerte e inacessível (GARGARELLA, 2015a, 2015b). 
Destarte, o que carece em alguns ordenamentos jurídicos atuais é uma participação efetiva e contundente da sociedade civil, dos cidadãos nas decisões políticas, econômicas e sociais de um país.

\section{SISTEMA DE FREIOS E CONTRAPESOS: UM SISTEMA POUCO INCLUSIVO}

O sistema de freios e contrapesos consiste nas competências complementares, isto é, os Poderes Judiciário, Legislativo e Executivo são independentes e harmônicos entre si, assim, cada Poder possui sua competência "originária" ou competência principal, porém existem as competências complementares, que consistem em um Poder fiscalizar ou corrigir o outro Poder, exercendo uma função "atípica" das suas funções originárias.

Esse sistema dos "checks and balances" (freios e contrapesos) nasceu nos Estados Unidos da América (EUA), como uma forma de evitar uma crise institucional, como afirma o professor Roberto Gargarella (2016), por isso, é um sistema criado intencionalmente com o objetivo de fazer com que os Poderes se corrijam, se controlem, se ajustem para que não ocorram ilegalidades e abusos de poder.

Em que pese a intenção do sistema de freios e contrapesos, o professor Gargarella afirma que é um sistema que exclui a participação pública na tomada de decisões, ou seja, é um sistema que extirpa a democracia inclusiva e deliberativa (GARGARELLA, 2016).

É importante fazer referência a uma prática de diálogo inovadora e cada vez mais frequente, que são as audiências públicas, isto é, a participação da sociedade civil (associação de consumidores, vítimas e dentre outros são ouvidos) nos processos de tomada de decisão.

É a linguagem do diálogo ou as "soluções dialógicas" que devem prevalecer no espaço público, segundo Gargarella, isto significa que a tomada de decisão deve ser feita por pessoas "diferentes do governo". O professor Gargarella critica o controle de constitucionalidade, o qual a última palavra está sempre com o Poder Judiciário, o que evita o constitucionalismo dialógico que permite a participação efetiva dos cidadãos. Enfim, o professor Gargarella propõe um sistema diverso do tradicional sistema de freios e contrapesos (GARGARELLA, 2016).

Primeiramente, o autor Roberto Gargarella discorre sobre o novo constitucionalismo dialógico, e conceitua-o como um processo de tomada de decisões em que se estabelece um diálogo inclusivo, ou seja, escuta-se toda a população, sem exceções. Deve-se escutar todos os 
posicionamentos, todas as opiniões, sejam elas convergentes ou divergentes. Assim, a tomada de decisão somente será plausível se houver um processo de discussão, o qual se inclua todos os cidadãos.

Essa ideia de novo constitucionalismo dialógico vem a calhar com o princípio da alteridade, aquele que consiste em respeitar e considerar o outro, com todas as suas diferenças, e ainda mais, por intermédio desse princípio, extrai-se que se deve olhar para o outro com o olhar do outro e não com o seu próprio olhar. Desta feita, a partir do momento que o novo constitucionalismo dialógico consiste em considerar o outro, isso remete ao princípio da alteridade.

Com efeito, o autor faz algumas críticas ao sistema tradicional dos freios e contrapesos, e o contrapõe com o novo constitucionalismo dialógico. O autor aborda sobre a falta de legitimidade que os três Poderes possuem, pois eles estão completamente desconectados da realidade social. O Poder Executivo, segundo Gargarella, é pautado pela discricionariedade, isto é, toma as decisões que reputar devido. O Poder Judiciário, como já citado, é a última palavra sobre a constitucionalidade ou não das leis, o que se mostra fragilizado sem a ratificação dos cidadãos, pois se torna um "monólogo ou uma supremacia judicial” e o Poder Legislativo, por sua vez, é uma "máquina de transmissão das decisões já elaboradas, já fechadas, advindas do Executivo". Portanto, o autor deixa claro que a tomada de decisões dentro dos três Poderes está eivada quando não ouve o clamor da sociedade.

$\mathrm{O}$ sistema de freios e contrapesos (checks and balances) nasceu em meio à crise institucional nos EUA, que tinham acabado de declarar a independência, então tinham acabado de passar por período de guerra, período de instabilidade econômica, e criou o sistema "checks and balances" com o escopo de evitar a tirania e a anarquia. $\mathrm{O}$ autor afirma que esse sistema foi editado com uma intenção benéfica, porém ele enseja uma democracia mais restritiva.

O autor Roberto Gargarella exemplifica o novo constitucionalismo dialógico em uma Câmara Legislativa na Pensilvânia, nos EUA, que por sua vez, introduziram uma novidade, qual seja, antes de qualquer projeto ser aprovado pela Câmara, faz-se uma discussão do projeto para os cidadãos, assim, dá-se transparência e publicidade aos projetos e procedimentos das leis.

O modelo do constitucionalismo dialógico rechaça as decisões que são tomadas sem o respaldo público, isto é, aquelas decisões baseadas em troca de favores e não na realidade pública são completamente desprovidas de legitimidade. 
O autor Gargarella se mostra insatisfeito com o sistema judiciário, o qual sempre a última palavra é do Tribunal, e este está sempre em posição superior, posição de comando, o que gera desigualdade no momento da tomada de decisão. Uma das partes no processo clama, se queixa, litiga enquanto a outra parte apenas decide, sendo que essa decisão é discricionária. Assim, as Cortes Judiciárias não são dialógicas.

O grande imbróglio desse sistema de freios e contrapesos é o distanciamento com a sociedade civil, é a falta de empatia com os cidadãos. Um exemplo que o autor traz são as consultas à população indígena, quando ocorre a exploração de lítio em seus territórios. O autor afirma que essas consultas são desprovidas de legitimidade, de credibilidade. São consultas informais e superficiais. Enfim, o que ocorre é o distanciamento entre a população indígena e o governo, pois os indígenas não mais acreditam na utilidade dessas consultas públicas, rejeitando-as ou dando as costas.

Outro problema apontado pelo autor é a influência do dinheiro, isto significa que as pessoas que possuem condição financeira são mais ouvidas do que as que são desprovidas de recursos financeiros.

Destarte, o autor afere que o sistema de freios e contrapesos não é o ideal para a plena participação pública na tomada de decisão. Ademais, o autor afirma que o voto não pode ser a única instância de controle popular ou o único meio de participação popular.

Em contrapartida, o novo constitucionalismo dialógico propõe a oitiva de todos os cidadãos, dentre eles, as minorias, as maiorias, para que assim a política seja guiada pelas reais necessidades e prioridades da coisa pública, da cidadania.

Atualmente, o sistema de freios e contrapesos não serve bem, precisa ser reformado, pois ele retira a participação pública das tomadas de decisões, deixando apenas aos Poderes para decidirem, e estes decidem com base na discricionariedade, ou seja, as decisões são pautadas pela conveniência e oportunidade, e não na real necessidade dos cidadãos (GARGARELLA, 2016).

A democracia deliberativa está pautada em dois pilares: diálogo (deliberação) e inclusão. O professor Gargarella diz que é preciso romper ou conquistar as portas da "sala de máquinas", que atualmente está concentrada nas mãos dos poderes centralizados, cada vez mais na mão da figura forte do presidente. Hodiernamente, há uma infinidade de direitos constituídos, contudo, há a falta do diálogo, da inclusão da população na tomada de decisão.

A democracia latino-americana precisa dar voz ao cidadão, ao cidadão excluído, marginalizado. Não necessariamente precisam ser os cidadãos a decidirem, o que é imperioso 
é que eles façam parte do processo deliberativo, de modo que sejam os protagonistas na tomada de decisão (GARGARELLA, 2015a, 2015b).

Isso posto, o constitucionalismo latino-americano já evoluiu, apesar de que precisa progredir ainda mais no sentido de permitir a real participação popular nas decisões públicas do país.

\section{CONCLUSÃO}

O constitucionalismo latino-americano passou por três fases, atualmente se encontra na terceira fase, a qual precisa ser aprimorada, por intermédio dos métodos de participação popular na tomada de decisão do país.

O novo constitucionalismo latino-americano prima pelo reconhecimento das pluralidades, da multiculturalidade, da emancipação popular, como formas de retirar o poder das mãos apenas das autoridades públicas e colocar nas mãos de cada indivíduo, o que lhes atribui a autonomia individual de participar das decisões políticas, econômicas, sociais, culturais do país.

Afirma-se que muitos aspectos desse atual constitucionalismo latino-americano precisam ser mudados, pois está assentado ainda em estruturas antigas que não permitem o acesso dos indivíduos de uma nação às decisões que lhes interessam.

O professor Roberto Gargarella faz críticas no sentido de que os povos de uma nação não possuem meios de alcançar a "sala de máquinas" da Constituição, em outras palavras, diz que os cidadãos não possuem participação direta nas decisões de extrema importância para o país, assim, esses cidadãos são relegados aos papéis secundários, e até mesmo são rebaixados à condição de meros expectadores das decisões advindas do alto Poder.

Outra crítica referida por Gargarella é quanto ao sistema de freios e contrapesos, o autor afirma que foi um sistema projetado com boas intenções, porém na prática é um instrumento que privilegia os Poderes da República, o que gera até mesmo o fenômeno do "hiperpresidencialismo", que se caracteriza como o Poder preponderantemente na mão do chefe do Executivo. Portanto, claramente, esse sistema incorre em erros quando não abre espaço para a participação popular.

Destarte, nota-se que o estágio atual do constitucionalismo latino-americano é no sentido de ter alcançado avanço quanto à implementação de direitos sociais, contudo no quesito 
organizacional do sistema político, ainda há falhas, pois sua organização está centrada na concentração do poder nas mãos das autoridades públicas, o que obsta a participação popular nas decisões públicas.

Enfim, é preciso facilitar a lógica do constitucionalismo dialógico. Por óbvio, não se tem uma receita pronta e acabada, o que se possui são possíveis articulações que possibilitam uma democracia deliberativa.

\section{REFERÊNCIAS BIBLIOGRÁFICAS:}

DEBATES VIRTUAIS. Constitucionalismo latino-americano e a sua sala de máquinas, Roberto Gargarella, $2018 . \quad$ Disponível em:https://www.debatesvirtuais.com.br/constitucionalismo-latino-americano-e-a-sua-sala-demaquinas-prof-da-uba-roberto-gargarella-dv-26/. Acesso em: 11 jan. 2018.

GARGARELLA, Roberto. Justiça dialógica e constitucionalismo latino-americano. Entrevista com o prof. Roberto Gargarella. Revista Culturas Jurídicas, Niterói, v.2, n. 3, 2015. Disponível em: http://www.culturasjuridicas.uff.br/index.php/rcj/article/view/124/43. Acesso em: 11 jan. 2019.

GARGARELLA, Roberto. La «sala de máquinas» de las constituciones latino-americanas: Entre lo viejo y lo nuevo. Revista Nueva Sociedad, n. 258, Julio - Agosto 2015.

GARGARELLA, Roberto. Latin American Constitutionalism 1810-2010 (2013).

GARGARELLA, Roberto. O novo constitucionalismo dialógico, frente ao sistema de freios e contrapesos. In: VIEIRA, José Ribas; LACOMBE, Margarida; LEGALE, Siddharta. Jurisdição constitucional e direito constitucional internacional. Belo Horizonte: Fórum, 2016. p. 37-75. ISBN 978-85-450-0196-6. Disponível em: 〈http://www.bidforum.com.br〉. 
HABERLE, Peter. Hermenêutica Constitucional - A Sociedade Aberta dos Intérpretes da Constituição: Contribuição para Interpretação Pluralista e "Procedimental" da Constituição. Tradução de Gilmar Ferreira Mendes. Sérgio Antônio Fabris Editor, 1997.

NINO, Carlos Santiago. Hyperpresidentialism and Constitutional Reform in Argentina. Em: LIJPHART, Arend; WAISMAN, Carlos H. Institutional Design in New Democracies: Eastern Europe and Latin America 161 (1996).

Publicação original: GARGARELLA, Roberto. Latin American Constitutionalism: Social Rights and the "Engine Room" of the Constitution. Notre Dame J. Int'L \& Comp. L., vol. 4, 2014, p. 9-18. Versão Reduzida de seu livro publicado em inglês e em espanhol sobre o mesmo tema: GARGARELLA, Roberto. La sala de máquinas de la Constitución: Dos siglos de constitucionalismo en América Latina (1810-2010). Buenos Aires: Katz Editores, 2014; GARGARELLA, Roberto. Latin American Constitutionalism (1810-2010): The Engine Room of the Constitution. New York: Oxford University Press, 2013. Trad. Jefferson Guedes e Thiago Pádua.

ROCHA, Marina Cristina Schmaltz. Marcos plurinacionais e multiculturais contemporâneos como limites ao poder constituinte originário e como forma de emancipação social. In: IV Congresso Internacional Constitucionalismo e Democracia: O Novo Constitucionalismo Latino-Americano: Socioambientalismo, Interculturalidade e Integração Latino-Americana para o Bem Viver. Foz do Iguaçu, Paraná, Brasil, 2014. Apresentação de Trabalho. 
